\title{
Practical Management of Stroke Prevention in Patients with Atrial Fibrillation and Renal Impairment Receiving Newer Oral Anticoagulants: Focus on Rivaroxaban
}

Jafna L Cox ${ }^{1-3^{*}}$

${ }^{1}$ Division of Cardiology, Queen Elizabeth II Health Sciences Centre, Halifax, Nova Scotia, Canada

${ }^{2}$ Department of Medicine and Department of Community Health and Epidemiology, Dalhousie University, Halifax, Nova Scotia, Canada

${ }^{3}$ Staff Cardiologist, Capital Health, Halifax, Nova Scotia, Canada

\begin{abstract}
Stroke is the most feared risk associated with atrial fibrillation (AF). Both stroke and bleeding risk are independently increased in patients with $\mathrm{AF}$ and renal dysfunction. The newer oral anticoagulants show similar or better stroke prevention without further bleeding risk compared with vitamin $\mathrm{K}$ antagonist therapy and without its numerous practical challenges. Nonetheless, renal monitoring is an important aspect of newer oral anticoagulant treatment. This paper reviews management of patients with $\mathrm{AF}$ and renal impairment receiving newer oral anticoagulants, with a specific focus on rivaroxaban given that it is now prescribed more often than warfarin by cardiologists in the US.
\end{abstract}

Keywords: Antithrombotic therapy; Arrhythmia; Cardiology; Renal disease; Kidney disease; Hematology

\begin{abstract}
Abbreviations: AF: Atrial Fibrillation; CCS: Canadian Cardiovascular Society; CHADS, Congestive Heart Failure, Hypertension, Age $\geq 75$ Years, Diabetes Mellitus, Stroke or Transient Ischemic Attack (doubled); $\mathrm{CHA}_{2} \mathrm{DS}_{2}$-VASc: Congestive Heart Failure/Left Ventricular Dysfunction, Hypertension, Age $\geq 75$ years (Doubled), Diabetes Mellitus, Stroke or Transient Ischemic Attack (Doubled), Vascular Disease, Age 65-74 Years, Sex category (Female); CKD: Chronic Kidney Disease; $\mathrm{CrCl}$ : Creatinine Clearance; CYP: Cytochrome P450; eGFR: Estimated Glomerular Filtration Rate; ESC: European Society of Cardiology; EU: European Union; HAS-BLED: Hypertension, Abnormal Renal/Liver Function, Stroke, Bleeding History or Predisposition, Labile International Normalized Ratio, Elderly ( $>65$ years), Drugs/alcohol; OAC: Oral Anticoagulant; PCC: Prothrombin Complex Concentrate; PD: Pharmacodynamic(s); PK: Pharmacokinetic(s); VKA: Vitamin K Antagonist
\end{abstract}

\section{Introduction}

Atrial fibrillation (AF) is the most common sustained arrhythmia of clinical significance and is estimated to affect $1-2 \%$ of the developed world's population [1-5]. Given that AF involves chaotic atrial activity with consequent deterioration of atrial mechanical function, AF predisposes patients to stasis-related atrial thrombi and is associated with a fivefold increase in the risk of stroke compared with individuals with normal sinus rhythm $[6,7]$.

Although relatively rare in people younger than 40 years of age, the prevalence of $\mathrm{AF}$ increases with age [4]. The incidence of $\mathrm{AF}$ doubles with each decade of life after 55 years of age such that the lifetime risk for developing $\mathrm{AF}$ is approximately 1 in 4 [4,8]. Renal impairment is another age-associated condition and, as such, often manifests concurrently with AF [9-11]. Thus, approximately one in three outpatients with AF have chronic kidney disease (CKD) [12], and patients with CKD are 2- to 3-timesmore likely to have AF (depending on the stage of CKD) than are patients with normal renal function [13].

Even though vitamin $\mathrm{K}$ antagonists (VKAs) continue to be advocated by current guidelines as an efficacious treatment for stroke prevention in most patients with non-valvular AF [14-16], the safety of oral anticoagulant (OAC) therapy in patients with $\mathrm{AF}$ and $\mathrm{CKD}$ remains unclear. Although CKD is associated with an increased risk of stroke in patients with $\mathrm{AF}, \mathrm{CKD}$ also increases the risk of bleeding associated with antithrombotic therapy [17-19]. Patients with severe renal impairment (creatinine clearance $[\mathrm{CrCl}] \leq 30 \mathrm{~mL} / \mathrm{min}$ ) were generally excluded from randomized controlled trials with anticoagulants, making it difficult to provide evidence-based recommendations for the use of such agents in patients with AF and severe renal impairment (Table 1) $[10,14]$. Indeed, one national guideline group recommended against any antithrombotic stroke prophylaxis whatsoever, including acetylsalicylic acid, for patients with the most compromised renal function $(\mathrm{CrCl}<15$ $\mathrm{mL} / \mathrm{min}$ and on dialysis) [14], given that the bleeding risk is so high and any stroke prophylaxis benefit is moderated by an otherwise limited prognosis. There is currently a large care gap between patients with $\mathrm{AF}$ who require OAC therapy and those who actually receive OAC therapy [20], and this gap is further exacerbated in patients with AF and renal impairment despite a higher, and broader, thromboembolic risk [21].

Compared with VKAs, the direct Factor Xa inhibitors (rivaroxaban, apixaban) and the direct thrombin inhibitor (dabigatran) have a quicker onset and offset of action, a more consistent anticoagulant effect, without need for routine coagulation monitoring or dose adjustment, andfewer interactions with food and other drugs [22]. Three of these agents (dabigatran, apixaban and rivaroxaban) now have clinical approval in many parts of the world for stroke prophylaxis in AF. All three agents are renally excreted to different degrees, and dose adjustments are recommended in patients with renal impairment (Table 1) [15]; however, only rivaroxaban has been evaluated at a reduced dose in patients with moderate renal impairment $(\mathrm{CrCl} \mathrm{30-49} \mathrm{mL} / \mathrm{min})$ [23]. This paper reviews the evidence with respect to the specific application

*Corresponding author: Jafna L Cox, Division of Cardiology, Queen Elizabeth II Health Sciences Centre, New Halifax Infirmary Site, Room 2147, 1796 Summer Street, Halifax, Nova Scotia, B3H 3A7, Canada, Tel: +1 902-473-7811; E-mail: jafna.cox@dal.ca

Received November 22, 2013; Accepted January 16, 2014; Published January 22, 2014

Citation: Cox JL (2014) Practical Management of Stroke Prevention in Patients with Atrial Fibrillation and Renal Impairment Receiving Newer Oral Anticoagulants: Focus on Rivaroxaban. J Gen Pract 2: 144. doi: 10.4172/2329-9126.1000144

Copyright: (c) 2014 Cox JL. This is an open-access article distributed under the terms of the Creative Commons Attribution License, which permits unrestricted use, distribution, and reproduction in any medium, provided the original author and source are credited. 


\begin{tabular}{|c|c|c|c|c|c|}
\hline \multirow{2}{*}{$\begin{array}{c}\text { Agent } \\
\text { (phase II trial) }\end{array}$} & \multirow{2}{*}{$\begin{array}{c}\mathrm{CrCl} \\
(\mathrm{mL} / \mathrm{min})\end{array}$} & \multirow{2}{*}{$\begin{array}{c}\text { Dose evaluated } \\
\text { at phase III trial }[23,33,41]\end{array}$} & \multicolumn{3}{|c|}{ Approved doses } \\
\hline & & & Canada $[42,54,95]$ & US $[36,56,96]$ & EU $[35,39,55]$ \\
\hline \multirow{4}{*}{$\begin{array}{l}\text { Rivaroxaban } \\
\text { (ROCKET AF) }\end{array}$} & $\geq 50$ & $20 \mathrm{mg}$ od & $20 \mathrm{md}$ od & $20 \mathrm{mg}$ od & $20 \mathrm{mg}$ od \\
\hline & $30-49$ & $15 \mathrm{mg}$ od & $15 \mathrm{mg} \mathrm{od}^{\star \star}$ & $\begin{array}{c}15 \mathrm{mg} \text { od } \\
(\mathrm{CrCl} 30-50 \mathrm{~mL} / \mathrm{min})\end{array}$ & $15 \mathrm{mg}$ od \\
\hline & $15-29$ & \multirow{2}{*}{ Excluded } & \multirow{2}{*}{ Not recommended } & $15 \mathrm{md} \mathrm{od}$ & $15 \mathrm{md} \mathrm{od}^{* \dagger}$ \\
\hline & $<15$ & & & Not recommended & Contraindicated \\
\hline \multirow{4}{*}{$\begin{array}{c}\text { Apixaban } \\
\text { (ARISTOTLE) }\end{array}$} & $\geq 50$ & $5 \mathrm{mg} \mathrm{bid}^{\ddagger}$ & $5 \mathrm{mg} \mathrm{bid}^{\ddagger}$ & $5 \mathrm{mg} \mathrm{bid}^{\ddagger}$ & $5 \mathrm{mg} \mathrm{bid} \ddagger$ \\
\hline & $30-49$ & $5 \mathrm{mg} \mathrm{bid}^{\ddagger}$ & $5 \mathrm{mg} \mathrm{bid}^{\ddagger}$ & $5 \mathrm{mg} \mathrm{bid}^{\ddagger}$ & $5 \mathrm{mg} \mathrm{bid}^{\ddagger}$ \\
\hline & $15-29$ & $\begin{array}{c}5 \mathrm{mg} \text { or } 2.5 \mathrm{mg} \text { bid if } \\
\geq 25 \mathrm{~mL} / \mathrm{min}^{\ddagger} \\
\text { (excluded if } \\
<25 \mathrm{~mL} / \mathrm{min} \text { ) }\end{array}$ & $\begin{array}{c}5 \mathrm{mg} \text { bid if } \geq 25 \mathrm{~mL} / \mathrm{min}^{\ddagger \S} \\
\text { (not recommended if } \\
15-24 \mathrm{~mL} / \mathrm{min} \text { ) }\end{array}$ & No clear recommendation & $2.5 \mathrm{mg} \mathrm{bid}$ \\
\hline & $<15$ & Excluded & Not recommended & Not recommended & Contraindicated \\
\hline \multirow{4}{*}{$\begin{array}{l}\text { Dabigatran } \\
\text { (RE-LY) }\end{array}$} & $\geq 50$ & \multirow{2}{*}{$\begin{array}{c}150 \mathrm{mg} \text { bid } \\
\text { or } 110 \mathrm{mg} \text { bid }\end{array}$} & \multirow{2}{*}{$150 \mathrm{mg}$ bid ${ }^{\Uparrow \S}$} & \multirow{2}{*}{$\begin{array}{c}150 \mathrm{mg} \mathrm{bid} \\
(\mathrm{CrCl}>30 \mathrm{~mL} / \mathrm{min})\end{array}$} & $\begin{array}{c}150 \mathrm{mg} \text { bid or } \\
110 \mathrm{mg} \mathrm{bid} \\
(\mathrm{CrCl}>50 \mathrm{~mL} / \mathrm{min})\end{array}$ \\
\hline & $30-49$ & & & & $\begin{array}{c}150 \mathrm{mg} \text { bid or } \\
110 \mathrm{mg} \mathrm{bid}+\pi \\
(\mathrm{CrCl} 30-50 \mathrm{~mL} / \mathrm{min})\end{array}$ \\
\hline & $15-29$ & \multirow[t]{2}{*}{ Excluded } & \multirow[t]{2}{*}{ Not recommended } & $\begin{array}{c}75 \mathrm{mg} \text { bid } \\
(\mathrm{CrCl} 15-30 \mathrm{~mL} / \mathrm{min})\end{array}$ & \multirow[t]{2}{*}{ Contraindicated } \\
\hline & $<15$ & & & Not recommended & \\
\hline
\end{tabular}

*Use with caution when close to $30 \mathrm{~mL} / \mathrm{min}$; †Use with caution; $\ddagger A$ reduced dose of $2.5 \mathrm{mg}$ bid is recommended with two or more of the following: age $\geq 80$ years, body weight $\leq 60 \mathrm{~kg}$ or serum creatinine $\geq 1.5 \mathrm{mg} / \mathrm{dl}$; ๆConsider dose adjustment for patients with a high bleeding risk; §Use with caution in patients with a CrCl of $30-49 \mathrm{~mL} /$ min, especially in the elderly or those with other risk factors for bleeding, and consider a lower dose of $110 \mathrm{mg}$ bid. bid, twice daily; CrCl, creatinine clearance; od, once daily.

Table 1: Tested and approved doses of newer oral anticoagulants in patients with mild, moderate and severe renal impairment.

of these drugs to patients with AF who have CKD. The paper focuses on the practical use of rivaroxabanin these patients,given that it is now prescribed by cardiologists in the US more often (40\%) than warfarin (35\%) [24].

\section{Novel Oral Anticoagulants}

Unlike VKAs, which acting directly on several components of the coagulation cascade, the newer OACs target specific coagulation factors [22]. These agents have received regulatory approval for the prevention of stroke and systemic embolism in patients with nonvalvular AF. All newer OACs, irrespective of their mode of action, have common properties, such as a rapid onset of action [22] and predictible pharmacokinetic (PK) profiles [25-30]; however, these OACs have some notable differences that will be reviewed.

\section{Dabigatran}

Dabigatran is administered as dabigatran etexilate, a prodrug. The dissolution and absorption of dabigatranin the stomach and small intestine is dependent on the presence of an acidic environment [31]; therefore, tartaric acid is included in the dabigatran tablet. Bioavailability is relatively low: approximately 6-7\% [25]. Dabigatranis primarily eliminated through renal clearance (by $\sim 80 \%$ ) [32]. Efficacy and safety endpoints between warfarin and dabigatran, at either the $150 \mathrm{mg}$ twice daily or $110 \mathrm{mg}$ twice daily dose, did not differ between the subgroup of 3505 patients in the RE-LY study (19\%)with a $\mathrm{CrCl}$ of $30-49 \mathrm{~mL} / \mathrm{min}$ and those with a $\mathrm{CrCl}$ of $50 \mathrm{~mL} / \mathrm{min}$ or more $[33,34]$. Nonetheless, because exposure to dabigatran increases with the severity of renal impairment [25], a dose reduction is recommended in patients with moderate renal impairment [22]. The European Union (EU) Summary of Product Characteristics recommends that a dose reduction from the standard dose of $150 \mathrm{mg}$ twice daily to $110 \mathrm{mg}$ twice daily should be considered for patients with a $\mathrm{CrCl}$ of $30-50 \mathrm{~mL} / \mathrm{min}$ and a high risk of bleeding (Table 1) [35]. The Prescribing Information recommends $150 \mathrm{mg}$ twice daily for patients with a $\mathrm{CrCl}$ above $30 \mathrm{~mL} / \mathrm{min}$ [36]. In most parts of the world, dabigatran is contraindicated in patients with severe renal impairment (estimated $\mathrm{CrCl} \leq 30 \mathrm{~mL} / \mathrm{min}$ ) [35-37]. In the US, a dose of $75 \mathrm{mg}$ twice daily is given as an option for patients with a $\mathrm{CrCl}$ of 15 $30 \mathrm{~mL} / \mathrm{min}$, although this is based on PK and pharmacodynamic (PD) data rather than clinical trial experience (Table 1). Known interactions of dabigatran with other drugs (e.g. strong inhibitors of the transporter P-glycoprotein) result in higher plasma concentrations; therefore, a dose reduction for patients receiving these drugs is recommended, together with close clinical surveillance, especially in patients with mild-to-moderate renal impairment $[35,36]$. The importance of regular monitoring of renal function has been highlighted by post-marketing reports of bleeding events during treatment with dabigatran in elderly patients with severe renal impairment [38].

\section{Apixaban}

Apixaban, as with rivaroxaban and other Factor Xa inhibitors that are still in development or under clinical assessment, has no prodrug. It has been shown to have predictable PK [27]. The absolute bioavailability of apixaban is $50 \%$ [39]. Apixaban is metabolized mostly via cytochrome P450 (CYP) 3A4 and is a substrate of P-glycoprotein; therefore, drugs that are strong inhibitors of both CYP3A4 and P-glycoprotein may significantly alter apixaban plasma concentrations and are not recommended for concomitant use. Elimination of apixaban is through multiple pathways including metabolism, the kidneys and the billiary system, although total renal clearance accounts for approximately half of the systemically available dose $[27,40]$. Of the $25 \%$ of administered dose excreted in the urine, more than $80 \%$ is unchanged drug. In a subgroup analysis of the ARISTOTLE trial, the 3017 patients (15\%) with an estimated glomerular filtration rate (eGFR) of $50 \mathrm{~mL} / \mathrm{min}$ or less achieved efficacy and safety outcomes that were at least equivalent to those in patients who had eGFRs greater than $50 \mathrm{~mL} / \mathrm{min} \mathrm{[19].}$ However, no specific data have been published for patients treated with apixaban with an eGFR or CrClof $25 \mathrm{~mL} /$ minor less (Table 1). In the ARISTOTLE study, a reduced dose of $2.5 \mathrm{mg}$ twice daily (instead of the standard $5 \mathrm{mg}$ twice-daily dose) was administered in 428 patients $(4.7 \%)$ in the apixaban group with two of the following: age $>80$ years, 
weight $<60 \mathrm{~kg}$ and serum creatinine $\geq 1.5 \mathrm{mg} / \mathrm{dl}(133 \mu \mathrm{mol} / \mathrm{L})[41]$. However, it is not clear how many of this relatively small cohort received the lower dose because of renal impairment. In the EU, apixaban is not recommended for use in patients with a $\mathrm{CrCl}$ below $15 \mathrm{~mL} / \mathrm{min}$ (Table 1) because no clinical data are available for these patients [39]. The EU Summary of Product Characteristics states that patients with exclusive criteria of severe renal impairment (defined as $\mathrm{CrCl} 15-29 \mathrm{~mL} / \mathrm{min}$ ) should receive the lower dose of apixaban $2.5 \mathrm{mg}$ twice daily, whereas the Canadian Monograph specifies that no dosing recommendation can be made in patients with a $\mathrm{CrCl}$ of $15-24 \mathrm{~mL} / \mathrm{min}$ because of "very limited" clinical data [42].

\section{Rivaroxaban}

Rivaroxaban has been found to have a predictable clinical pharmacology profile $[30,43]$ and PD that correlates with plasma concentrations [43]. Similar to apixaban, the metabolism of rivaroxaban is via CYP3A4 and rivaroxabanis a substrate of P-glycoprotein; therefore, drugs that are strong inhibitors of both CYP3A4 and P-glycoprotein are not recommended for concomitant use. Rivaroxaban has a dual mode of elimination: two-thirds of the drug undergoes metabolic degradation in the liver, half of which is excreted via the kidneys and the other half via the hepatobiliary route; the remaining one-third of the dose is excreted as unchanged drug in the urine [43]. The use of rivaroxaban in patients with renal impairment is discussed below.

\section{Risk Stratification}

Treatment guidelines for AF uniformly recommend that all affected patients are stratified using a predictive index for the risk of stroke (e.g. $\mathrm{CHADS}_{2}$ [44] or CHA DS 2 VASc [45]) and for bleeding (e.g. HAS-BLED [46]) and that most patients should receive antithrombotic therapy to prevent stroke unless the bleeding risk is excessive [14-16]. Although $\mathrm{CHADS}_{2}$ or $\mathrm{CHA}_{2} \mathrm{DS}_{2}$ VASc score can only increase (with age or the accumulation of additional risk), bleeding risk can rise but can also be lowered. In the case of HAS-BLED, discontinuation of antiplatelet medication or alcohol, optimization of international normalized ratio control and improvement in renal or hepatic function, where possible, can all reduce bleeding risk. As such, an elevated bleeding risk should not generally lead to avoidance of treatment with OAC, because the risk of bleeding rarely outweighs the elevated risk of stroke; instead, it should prompt the physician to reduce bleeding risk and to increase careful monitoring of the patient for blood loss.

The recommendation to stratify patients according to their stroke and bleeding risk and to consider these relative hazards in subsequent therapeutic decision making applies equally to patients with and without renal impairment $[10,47]$. However, it should be noted that bleeding risk increases as kidney function worsens [48] such that anticoagulant use, indeed the use of any antithrombotic, becomes controversial in patients with extremely poor renal function, such as those with a $\mathrm{CrCl}$ below $15 \mathrm{~mL} / \mathrm{min}$, especially those on dialysis [14]. Thus, all patients, but especially those with moderate or severe renal impairment, need careful evaluation and the ultimate decision for use of oral anticoagulation to be based on individual risk stratification. Although not included in the $\mathrm{CHADS}_{2}$ and $\mathrm{CHA}_{2} \mathrm{DS}_{2}$. VASc scores, renal impairment increases the risk of stroke in patients with AF [17-19]. Abnormal renal function is included in the bleeding risk scores [46,49]. If the risk of stroke is deemed to outweigh the risk of bleeding, OAC treatment should be considered $[10,50]$. Furthermore, regular and ongoing monitoring of renal function should become routine in the management of patients with AF. Special attention should be given to the elderly or in patients with borderline renal function at baseline who might be prone to sudden drops in $\mathrm{CrCl}$ or eGFR with dehydration or acute illness. Thus, the Canadian Cardiovascular Society (CCS) guidelines recommend annually assessing renal function in patients with $\mathrm{AF}$ who are receiving OAC therapy [14]. More frequent measurements should be considered in patients who require a reduced $\mathrm{OAC}$ dose, such as those with a $\mathrm{CrCl}$ less than $60 \mathrm{~mL} / \mathrm{min}$ or with conditions that may transiently reduce eGFR [51]. This is especially true in patients older than 75 years [14,52]. In the European Society of Cardiology (ESC) 2012 guidelines update, assessment of renal function (by $\mathrm{CrCl}$ ) is considered mandatory with use of all newer OACs and should be performed annually in patients with normal $(\mathrm{CrCl} \geq 80 \mathrm{~mL} / \mathrm{min})$ or mild $(\mathrm{CrCl} 50-79 \mathrm{~mL} / \mathrm{min})$ renal impairment and perhaps 2-3 times a year in patients with moderate renal impairment $(\mathrm{CrCl} 30-49 \mathrm{~mL} / \mathrm{min})$ [15].

\section{Rivaroxaban in Patients with Renal Impairment}

When considering rivaroxaban for long-term management, renal function should be estimated by determining $\mathrm{CrCl}$ using the Cockcroft-Gault formula before initiating therapy and then as often as needed thereafter [52]. One-third of the rivaroxaban dose is eliminated as unchanged drug in the urine [43]. A moderate increase in plasma exposure and PD effects were observed with rivaroxaban $10 \mathrm{mg}$ when given to patients with increasing renal impairment [53]. However, this is expected for a drug with partial renal excretion. The more important finding was that the influence of renal function on rivaroxaban clearance was moderate; thus, the extent of increased plasma exposure is unlikely to be of clinical relevance [53], even in patients with severe renal impairment. As such, no dose adjustments are necessary for mild renal impairment $(\mathrm{CrCl} 50-80 \mathrm{~mL} / \mathrm{min})$ [54-56].

\section{Use of rivaroxaban in patients with atrial fibrillation and moderate renal impairment}

Because rivaroxaban clearance is influenced by renal function [57], the daily dose of rivaroxaban in the ROCKET AF trial was reduced from $20 \mathrm{mg}$ once daily to $15 \mathrm{mg}$ once daily in patients with moderate renal impairment $(\mathrm{CrCl} 30-49 \mathrm{~mL} / \mathrm{min})$ at baseline [23]. A PK/PD analysis of simulated patients with AF supported this dose reduction, suggesting that the reduced dose would result in similar rivaroxaban exposure in patients with moderate impairment as with the $20 \mathrm{mg}$ once-daily dose in patients with healthy renal function [57]. A sub analysis of $2950(20.7 \%)$ patients with moderate renal impairment who were treated as part of the ROCKETAF trial found that the rivaroxaban dose adjustment yielded efficacy and safety results consistent with the overall trial in comparison with dose-adjusted warfarin [18]. The dose adjustment in patients with moderate renal impairment meant that the treatment effect for rivaroxaban versus warfarin in these patients was similar to that observed in patients with a $\mathrm{CrCl} \geq 50 \mathrm{~mL} / \mathrm{min}$ for both the primary efficacy endpoint and principal safety outcome. Compared with warfarin treatment in patients with moderate renal impairment, fatal bleeding (hazard ratio: 0.39; 95\% confidence interval: 0.15-0.99) and critical organ bleeding (hazard ratio: $0.55 ; 95 \%$ confidence interval: 0.30-1.00) were less frequent with rivaroxaban $15 \mathrm{mg}$ once daily. Therefore, a dose reduction from $20 \mathrm{mg}$ once daily to $15 \mathrm{mg}$ once daily is recommended for patients with moderate renal impairment in both the $\mathrm{EU}(\mathrm{CrCl} 30-49 \mathrm{~mL} / \mathrm{min})$ [55] and US labels $(\mathrm{CrCl} 30-50 \mathrm{~mL} / \mathrm{min})$ [56] Rivaroxaban should be used with caution in patients with moderate renal impairment who are concomitantly receiving drugs known to alter rivaroxaban plasma concentrations (e.g. potent inhibitors of CYP3A4) [55] or drugs that might worsen renal function (e.g. diuretics or angiotensin-convertingenzyme inhibitors or angiotensin II receptor blockers). 


\section{Use of rivaroxaban in patients with atrial fibrillation and severe renal impairment}

Both the CCS and the ESC 2012 guideline updates recommend against the use of the newer OACs in patients with a CrClbelow $30 \mathrm{~mL} / \mathrm{min}[14,15]$ given that patients with this severity of renal impairment were excluded from phase III trials. However, there may be some flexibility for physicians regarding these patients. Limited data in patients with a CrClof $15-29 \mathrm{~mL} / \mathrm{min}$ indicate that rivaroxaban plasma concentrations are increased significantly at this level of renal dysfunction [53], but the extent of therapeutic effect may not be of clinical relevance. Therefore, the EU Summary of Product Characteristics [55] states that rivaroxaban $15 \mathrm{mg}$ once daily should be used with caution in patients with a CrClof $15-29 \mathrm{~mL} / \mathrm{min}$ (Table 1 ), but only after a careful and considered benefit-risk assessment is undertaken before and during treatment [52]. No dose adjustment is necessary for elderly patients [55], although experts suggest that the renal function of patients aged $>75$ years should be monitored regularly [52].

\section{When should a possible decline in renal function be considered?}

Although it may be challenging to predict declining renal function, there are conditions and circumstances whose presence should at least heighten concern about this possibility. Many risk factors for acute kidney injury have been identified [58], including patient age [59], sepsis [60], previous cardiac surgery [61,62], contrast dye [63], diabetes $[64,65]$, rhabdomyolysis [66], pre-existing renal disease $[67,68]$, hypovolemia [69] and shock [69]. From a more practical perspective, renal failure can result from pre-renal, intra-renal or post-renal causes, with pre-renal etiologies accounting for $60-70 \%$ of cases [70]. Intravascular volume depletion, often manifesting subsequent to fever, vomiting and diarrhoea, is the most common cause of pre-renal failure. When serious, it can lead to decreased kidney perfusion; however, dehydration from any cause, including diuretics, can lead to acute renal failure [70]. The initial assessment should include the patients' history to identify systemic illnesses or the use of nephrotoxic medications that might cause poor renal perfusion or directly impair renal function. Older patients, who often have a preceding age-related decline in renal function, have a higher risk of developing acute renal insufficiency or experiencing a worsening of any pre-existing renal impairment, and therefore require the most careful surveillance.

Even in the absence of any acute kidney injury, inappropriate dosing in patients with CKD can cause ineffective therapy. By itself, CKD can affect glomerular blood flow and filtration, tubular secretion and re-absorption, and renal bioactivation and metabolism. As a result, drug absorption, bioavailability, protein binding, distribution volume and non-renal clearance (metabolism) can be altered in these patients. Physicians should pay careful attention when considering drug therapies with active or toxic metabolites that can accumulate and contribute to exaggerated pharmacological effects or adverse drug reactions in patients with CKD.

The simple monitoring of serum creatinine levels is routine in practice and is used in the HAS-BLED bleeding risk score [46]. However, because the elderly tend to have decreased muscle mass, this method of assessment can be an inadequate measure of renal function. Up to $40 \%$ of patients aged 65 years or older have at least modest renal insufficiency, defined as an eGFR below $60 \mathrm{~mL} / \mathrm{min}$ using the Cockcroft- Gault formula [71]. Thus, assessment of renal function needs to take both age and weight into account rather than just serum creatinine alone. Unfortunately, this is not often performed despite the fact that many medications (including antibiotics, antihypertensives, fibrates, sedatives/hypnotics and anxiolytics) are cleared through the kidneys and dosing guidelines require dosage adjustments in patients with decreased $\mathrm{CrCl}$ [72]. Aggravating matters is the fact that older patients tend to be taking multiple drugs at any given time, making assessment difficult. A national survey from the US reported that the average nursing home resident used seven to eight different medications each month whereas approximately one in three patients used nine or more different medications [73]. In a study in Canada, $62 \%$ of patients older than 65 years of age on public drug programmes had claims for five or more drugs and $5.5 \%$ had claims for 15 or more [74]. Furthermore, the number of drug classes used increased with age, such that $28.6 \%$ of patients aged 85 years or older had claims for 10 or more drugs classes versus $16.8 \%$ for those aged between 65 and 74 years [74]

Given that renal impairment becomes more prevalent with increasing age, it is unsurprising that failure to adjust properly for renal insufficiency is a common cause of dose-related adverse events among the elderly [75]. Adverse events relating to warfarin, specifically bleeding, have been especially common [76]. Thus, not only should $\mathrm{CrCl}$ or eGFR be monitored more frequently, dose adjustment (generally lowering the dose) should follow as necessary, with the potential for resumption of the regular dose if and when renal function recovers.

\section{Management of bleeding events}

In cases of bleeding, rivaroxaban (as with any OAC) should be discontinued or the next dose delayed, according to established bleeding management protocols (Figure 1) [77]. If bleeding is mild, missing only a single dose will quickly reverse the anticoagulant effect because of the short half-life of rivaroxaban (5-13 hours) $[43,55,78]$. If bleeding continues, then the local cause of bleeding must be investigated. If possible, any concomitant antiplatelet drugs should be stopped. If bleeding continues, then drug accumulation should be considered. Patients receiving rivaroxaban should have their prothrombin time measured [78]. The prothrombin time shows a linear dose-response to rivaroxaban and is prolonged; however, this is assay dependent $[43,79]$. Thus, an elevated prothrombin time is a useful qualitative indicator of drug presence, but does not provide precise information on drug level and hence the anticoagulant effect. A normal prothrombin time in the setting of rivaroxaban use would suggest that hemostatic function is not impaired because of the drug. Renal function should also be assessed, via $\mathrm{CrCl}$ or eGFR, as a potential contributor to an increased risk of bleeding. In patients with impaired renal function and bleeding, dose reduction or drug discontinuation should be considered as appropriate [55].

With moderate or severe bleeding, it is imperative to halt anticoagulation treatment and investigate the source of bleeding (Figure 1). Every effort should be taken to control bleeding with pressure or surgical hemostasis. Again, measurement of prothrombin time will indicate if rivaroxaban was taken, but will not provide insight into the anticoagulant effect. Although there is very little clinical evidence (e.g. randomized trials), consideration should be given to the administration of whole blood, fresh frozen plasma or platelet concentrates (in the setting of thrombocytopenia or if antiplatelet drugs had been taken) [55]. Prothrombin complex concentrates (PCCs), activated PCCs, recombinant Factor VIIa, or concentrates of Factors II, IX or X might also be considered, although again there is insufficient clinical experience with such approaches $[51,78]$. There is no literature either supporting or contraindicating the use of such treatment in patients 


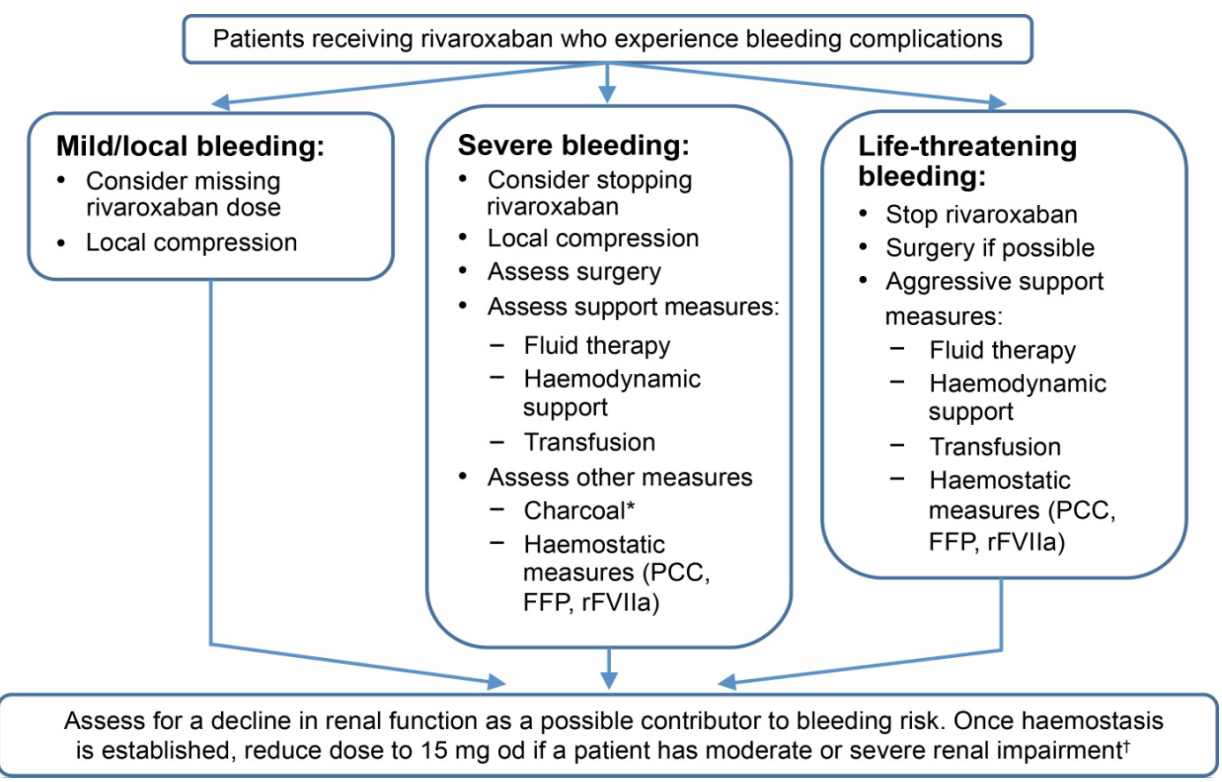

Figure 1: Management of bleeding in patient with AF receiving rivaroxaban.

AF: Atrial Fibrillation; FFP: Fresh Frozen Plasma; od: Once Daily; PCC: Prothrombin Complex Concentrate; rFVIla: Recombinant Factor VIla. *If within 2 hours of tablet intake; $+\mathrm{CrCl} 15-49 \mathrm{~mL} / \mathrm{min}$; use with caution if $15-29 \mathrm{~mL} / \mathrm{min}$ [52].

with markedly impaired renal function. Note that hemodialysis or hemofiltration should not be considered because rivaroxaban is highly protein bound and, as such, is unlikely to be dialyzable $[79,80]$.

An advantage of rivaroxaban, as with the other newer OACs, is its short half-life so that supportive measures will only be required for a short time; in contrast, the half-life of warfarin is 20-60 hours [22]. There is currently no antidote for rivaroxaban or the other newer OACs; however, there is also no rapidly-acting antidote for warfarin. Administration of vitamin $\mathrm{K}$ will reverse the anticoagulant effect of warfarin, but this takes a long time to work ( $>6$ hours in $54 \%$ of patients with intravenous administration [81]); far too long if the patient is presenting with an intracranial hemorrhage, for example. After vitamin $\mathrm{K}$ administration, increased synthesis of coagulation factors begins within 1-3 hours; however, the clinical effect is not detected until after 4-6 hours, with the maximum effect only seen after 24-36 hours [82]. Although PCCs rapidly correct international normalized ratio in most patients receiving warfarin, this insufficiently impacts prognosis, at least in patients with intracranial hemorrhage for whom mortality and morbidity rates remain high [83]. It has also been suggested that there is a risk of thromboembolic complications with PCC use in VKA-treated patients [84]. There is considerable effort being made to develop reversal agents for both the direct Factor Xa and direct thrombin inhibitor drugs and the expectation is that such products will soon become available. One possible Factor Xainhibitor antidote, PRT064445 (r-Antidote), has demonstrated dose-dependent reversal of Factor Xa inhibition by rivaroxaban and apixaban (and a third agent, betrixaban) in Factor Xa enzyme assays. In this study, PRT064445 alleviated blood loss resulting from rivaroxaban-induced anticoagulation in a rabbit liver laceration model [85]. PRT064445 is currently being evaluated in a phase II trial in healthy volunteers who have been administered one of four direct/ indirect Factor Xa inhibitors, including rivaroxaban $[86,87]$.

\section{Perioperative management}

Alteration of the OAC regimen may not be necessary for most patients undergoing low-risk procedures, such as dental procedures (including extractions of up to four teeth), joint and soft tissue injections, arthrocentesis, cataract surgery, upper endoscopy or colonoscopy with or without biopsy $[88,89]$. For other invasive and surgical procedures, oral anticoagulation needs to be withheld and a clinical decision reached on whether to pursue an aggressive strategy of perioperative administration of intravenous heparin or subcutaneous low molecular weight heparin. This decision should be individualized based on an estimation of the patient's risks of thromboembolism and bleeding $[88,89]$.

From a practical perspective, any patient taking an OAC and requiring surgery should have their renal function assessed, in conjunction with a consideration of the half-life of their anticoagulant agent, and the relative risk of stroke versus bleeding [51]. Together, these matters will inform decisions around the timing of any temporary drug discontinuation, the need for bridging therapy, and when therapy should be resumed and, potentially, at what dose.

For rivaroxaban in particular, the recommendation is to withhold the drug for at least 24 hours before the procedure in patients with a low risk of bleeding and then to restart it once hemostasis is established [51,55]. For patients with a $\mathrm{CrCl}$ of $15-30 \mathrm{~mL} / \mathrm{min}$, it has been recommended that the delay is at least 36 hours, even when there is a low risk of bleeding [51]. For procedures associated with a high risk of bleeding (or for patients at high risk of bleeding) it has also been recommended that the procedure be delayed by at least 48 hours after the last dose (Figure 2) [51,77]. Again, a patient's renal function and stroke risk should also be considered, as well as their bleeding risk (Figure 2). As mentioned at the beginning of this section, for non-invasive or superficial procedures, treatment with rivaroxaban may be maintained, 


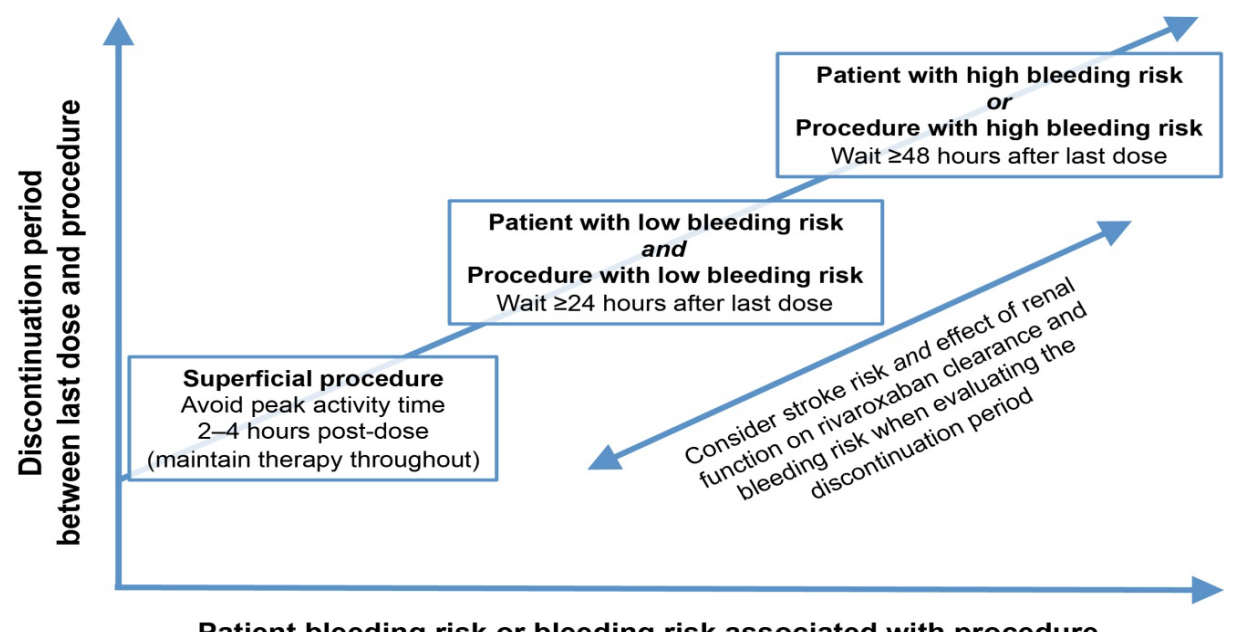

Patient bleeding risk or bleeding risk associated with procedure

Figure 2: When to discontinue rivaroxaban therapy before an elective procedure.

avoiding times of rivaroxaban peak activity (2-4 hours post dose) [52]. For urgent procedures, physicians should consider the increased risk of bleeding against the urgency of the procedure and delay at least 24 hours if possible [51,54-56]. The physician should again consider the patient's renal function and the effect this may have on rivaroxaban clearance. Patients with a $\mathrm{CrCl}$ of $15-49 \mathrm{~mL} / \mathrm{min}$ after the procedure should be switched to the $15 \mathrm{mg}$ dose (if not already on this dose) [55] or switched to warfarin for at least a while after the procedure. This is in contrast to dabigatran, which may need to be stopped at least 4 or 5 days before a procedure in patients with poor renal function and high bleeding risk because of its greater dependence on renal clearance and the consequent effect this has in terms of prolonging drug half-life $[35,51,90]$.

\section{Measuring Rivaroxaban in Patients}

Because of their predictable pharmacology, routine coagulation monitoring of newer OACs is not required $[22,91]$. In patients with renal impairment, advanced age and clinically relevant drug-drug interactions, periodic laboratory drug measurement may be appropriate [92]. Under such circumstances, quantitative measurements of rivaroxaban can be taken using an anti-Factor Xa chromogenic assay; rivaroxaban-specific calibrators and controls (commercially available, e.g. from Technoclone or Hyphen-BioMed) should be used for calibration, with results expressed as $\mathrm{ng} / \mathrm{mL}$ of rivaroxaban [52]. However, these measurements are expensive and not readily available. In the meantime, routine monitoring of rivaroxaban and the other anticoagulants is not available and, although not required for therapeutic efficacy, this would facilitate monitoring of patient adherence. Until readily available and affordable monitoring tools become available, prescribers should take the time to educate patients with regard to the therapeutic intent of these drugs, specifically the aim to prevent severe, often disabling stroke in patients with $\mathrm{AF}$, and to underline that this benefit is only to be achieved if the drugs are taken as prescribed. For patients for whom there is adherence concern, oncedaily dosing may be preferable because this has been shown to improve patient adherence to therapy versus twice-daily dosing $[93,94]$. Oncedaily dosing is therefore expected to promote compliance with newer OAC therapy in patients with AF [51].

\section{Discussion}

$\mathrm{AF}$ is an increasingly prevalent condition whose most feared complication is a major ischemic stroke. Available OACs are all highly effective at reducing the risk of stroke, albeit with a potential slight increase in bleeding, compared with no treatment. Although bleeding risk must be respected, it should not be overestimated or overemphasized. As with every aspect of care, clinical judgement of risk versus benefit needs to be considered, and bleeding risk is rarely sufficiently high as to outweigh the benefit of stroke risk reduction. Renal impairment is intimately associated with AF, being very common in the older patient cohorts most likely to develop AF. However, CKD is independently associated with increased stroke risk and increased bleeding risk [17-19]. Accordingly, in the subgroup of patients with $\mathrm{AF}$ and $\mathrm{CKD}$, greater attention to the benefit-risk assessment of antithrombotic treatment is warranted, especially when drugs have some renal-dependent clearance. With appropriate monitoring of renal function and dose adjustment, rivaroxaban is an important option for preventing stroke in patients with $\mathrm{AF}$ and impaired renal function (with a reduced dose available for these patients), while placing them at similar or less risk of bleeding than with VKA or other established antithrombotic therapies.

\section{Conflict of Interest}

Dr. Cox has served on advisory boards for AstraZeneca, Bayer, Boehringer Ingelheim, BMS, Pfizer and Sanofi-Aventis; has participated in research funded by Bayer, Merck, Pfizer and Sanofi-Aventis; has served as/is a consultant to the Nova Scotia Department of Health, the New Brunswick Department of Health and the Public Health Agency of Canada; was an external expert to the Canadian Agency for Drugs and Technologies in Health in their reviews of antithrombotic therapies in atrial fibrillation; and is a member of the Canadian Cardiovascular Society's Atrial Fibrillation Guidelines Panel and Chair of its Atrial Fibrillation Quality Indicator Subcommittee.

\section{Acknowledgement}

The author would like to acknowledge Joanne McGrail who provided editorial support with funding from Bayer HealthCare and Janssen Research \& Development, LLC. 
Citation: Cox JL (2014) Practical Management of Stroke Prevention in Patients with Atrial Fibrillation and Renal Impairment Receiving Newer Oral Anticoagulants: Focus on Rivaroxaban. J Gen Pract 2: 144. doi: 10.4172/2329-9126.1000144

\section{References}

1. Feinberg WM, Blackshear JL, Laupacis A, Kronmal R, Hart RG (1995) Prevalence, age distribution, and gender of patients with atrial fibrillation. Analysis and implications. Arch Intern Med 155: 469-473.

2. Go AS, Hylek EM, Phillips KA, Chang Y, Henault LE, et al. (2001) Prevalence of diagnosed atrial fibrillation in adults: national implications for rhythm management and stroke prevention: the Anticoagulation and Risk Factors in Atrial Fibrillation (ATRIA) Study. JAMA 285: 2370-2375.

3. Friberg J, Scharling H, Gadsbøll N, Jensen GB (2003) Sex-specific increase in the prevalence of atrial fibrillation (The Copenhagen City Heart Study). Am J Cardiol 92: 1419-1423.

4. Miyasaka Y, Barnes ME, Gersh BJ, Cha SS, Bailey KR, et al. (2006) Secular trends in incidence of atrial fibrillation in Olmsted County, Minnesota, 1980 to 2000 , and implications on the projections for future prevalence. Circulation 114: $119-125$

5. Lip GYH, Brechin CM, Lane DA (2012) The global burden of atrial fibrillation and stroke: a systematic review of the epidemiology of atrial fibrillation in regions outside North America and Europe. Chest 142: 1489-1498.

6. Wolf PA, Abbott RD, Kannel WB (1991) Atrial fibrillation as an independent risk factor for stroke: the Framingham Study. Stroke 22: 983-988.

7. Hart RG, Halperin JL, Pearce LA, Anderson DC, Kronmal RA, et al. (2003) Lessons from the stroke prevention in atrial fibrillation trials. Ann Intern Med 138: $831-838$.

8. Lloyd-Jones DM, Wang TJ, Leip EP, Larson MG, Levy D, et al. (2004) Lifetime risk for development of atrial fibrillation: the Framingham Heart Study. Circulation 110: 1042-1046.

9. Atar I, Konas D, Acikel S, Kulah E, Atar A, et al. (2006) Frequency of atria fibrillation and factors related to its development in dialysis patients. Int $J$ Cardiol 106: 47-51.

10. Reinecke H, Brand E, Mesters R, Schabitz WR, Fisher M, et al. (2009) Dilemmas in the management of atrial fibrillation in chronic kidney disease. $J$ Am Soc Nephrol 20: 705-711.

11. Soliman EZ, Prineas RJ, Go AS, Xie D, Lash JP, et al. (2010) Chronic kidney disease and prevalent atrial fibrillation: the Chronic Renal Insufficiency Cohort (CRIC). Am Heart J 159: 1102-1107.

12. Go AS, Fang MC, Udaltsova N, Chang Y, Pomernacki NK, et al. (2009) Impact of proteinuria and glomerular filtration rate on risk of thromboembolism in atria fibrillation: the anticoagulation and risk factors in atrial fibrillation (ATRIA) study. Circulation 119: 1363-1369.

13. Baber U, Howard VJ, Halperin JL, Soliman EZ, Zhang X et al. (2011) Association of chronic kidney disease with atrial fibrillation among adults in the United States: Reasons for Geographic and Racial Differences in Stroke (REGARDS) Study. Circ Arrhythm Electrophysiol 4: 26-32.

14. Skanes AC, Healey JS, Cairns JA, Dorian P, Gillis AM, et al. (2012) Focused 2012 update of the Canadian Cardiovascular Society atrial fibrillation guidelines: recommendations for stroke prevention and rate/rhythm control. Can J Cardiol 28: $125-136$

15. Camm AJ, Lip GYH, De Caterina R, Savelieva I, Atar D, et al. (2012) 2012 focused update of the ESC Guidelines for the management of atrial fibrillation: an update of the $2010 \mathrm{ESC}$ Guidelines for the management of atrial fibrillation. Developed with the special contribution of the European Heart Rhythm Association. Eur Heart J 33: 2719-2747.

16. Fuster V, Ryden LE, Cannom DS, Crijns HJ, Curtis AB, et al. (2011) 2011 ACCF/AHA/HRS focused updates incorporated into the ACC/AHA/ESC 2006 guidelines for the management of patients with atrial fibrillation: a report of the American College of Cardiology Foundation/American Heart Association Task Force on Practice Guidelines. Circulation 123: e269-e367.

17. Olesen JB, Lip GYH, Kamper AL, Hommel K, Køber L, et al. (2012) Stroke and bleeding in atrial fibrillation with chronic kidney disease. $\mathrm{N}$ Engl $\mathrm{J}$ Med 367: 625-635.

18. Fox KAA, Piccini JP, Wojdyla D, Becker RC, Halperin JL, et al. (2011) Prevention of stroke and systemic embolism with rivaroxaban compared with warfarin in patients with non-valvular atrial fibrillation and moderate renal impairment. Eur Heart J 32:2387-2394.

19. Hohnloser SH, Hijazi Z, Thomas L, Alexander JH, Amerena J, et al. (2012) Efficacy of apixaban when compared with warfarin in relation to renal function in patients with atrial fibrillation: insights from the ARISTOTLE trial. Eur Heart J 33: $2821-2830$
20. Ogilvie IM, Newton N, Welner SA, Cowell W, Lip GYH (2010) Underuse of ora anticoagulants in atrial fibrillation: a systematic review. Am J Med 123: 638-645

21. Piccini JP, Hernandez AF, Zhao X, Patel MR, Lewis WR, et al. (2009) Quality of care for atrial fibrillation among patients hospitalized for heart failure. J Am Coll Cardiol 54: 1280-1289.

22. Poulsen BK, Grove EL, Husted SE (2012) New oral anticoagulants: a review of the literature with particular emphasis on patients with impaired renal function. Drugs 72: 1739-1753.

23. Patel MR, Mahaffey KW, Garg J, Pan G, Singer DE, et al. (2011) Rivaroxaban versus warfarin in nonvalvular atrial fibrillation. N Engl J Med 365: 883-891.

24. Medpage Today (2013) 2-Year-Old Drug Takes Top Rx Slot from Warfarin.

25. Blech S, Ebner T, Ludwig-Schwellinger E, Stangier J, Roth W (2008) The metabolism and disposition of the oral direct thrombin inhibitor, dabigatran, in humans. Drug Metab Dispos 36: 386-399.

26. Stangier J, Clemens A (2009) Pharmacology, pharmacokinetics, and pharmacodynamics of dabigatran etexilate, an oral direct thrombin inhibitor. Clin Appl Thromb Hemost 15 Suppl 1: 9S-16S

27. Raghavan N, Frost CE, Yu Z, He K, Zhang H et al. (2009) Apixaban metabolism and pharmacokinetics after oral administration to humans. Drug Metab Dispos 37: $74-81$

28. Frost C, Wang J, Nepal S, Schuster A, Barrett YC, et al. (2013) Apixaban, an oral, direct Factor $\mathrm{Xa}$ inhibitor: single-dose safety, pharmacokinetics, pharmacodynamics and food effect in healthy subjects. $\mathrm{Br} \mathrm{J}$ Clin Pharmacol 75: $476-487$

29. Mueck W, Becka M, Kubitza D, Voith B, Zuehlsdorf M (2007) Population mode of the pharmacokinetics and pharmacodynamics of rivaroxaban - an oral, direct Factor Xa inhibitor - in healthy subjects. Int J Clin Pharmacol Ther 45: 335-344.

30. Kreutz R (2012) Pharmacodynamic and pharmacokinetic basics of rivaroxaban Fundam Clin Pharmacol 26: 27-32.

31. Eisert WG, Hauel N, Stangier J, Wienen W, Clemens A, et al. (2010) Dabigatran an oral novel potent reversible nonpeptide inhibitor of thrombin. Arterioscle Thromb Vasc Biol 30: 1885-1889.

32. Stangier J, Rathgen K, Stahle H, Mazur D (2010) Influence of renal impairment on the pharmacokinetics and pharmacodynamics of oral dabigatran etexilate: an open-label, parallel-group, single-centre study. Clin Pharmacokinet 49: 259268

33. Connolly SJ, Ezekowitz MD, Yusuf S, Eikelboom J, Oldgren J, et al. (2009) Dabigatran versus warfarin in patients with atrial fibrillation. N Engl J Med 361 1139-1151.

34. Eikelboom JW, Wallentin L, Connolly SJ, Ezekowitz M, Healey JS, et al. (2011) Risk of bleeding with 2 doses of dabigatran compared with warfarin in older and younger patients with atrial fibrillation: an analysis of the randomized evaluation of long-term anticoagulant therapy (RE-LY) trial. Circulation 123: 2363-2372.

35. Boehringer Ingelheim International $\mathrm{GmbH}$ (2013) Pradaxa ${ }^{\circledR}$ (dabigatran etexilate) Summary of Product Characteristics.

36. Boehringer Ingelheim Pharmaceuticals Inc (2013) Pradaxa ${ }^{\circledR}$ (dabigatran etexilate) Prescribing Information.

37. You JJ, Singer DE, Howard PA, Lane DA, Eckman MH, et al. (2012) Antithrombotic therapy for atrial fibrillation: Antithrombotic therapy and prevention of thrombosis, 9th ed: American College of Chest Physicians evidence-based clinical practice guidelines. Chest 141: e531S-e575S.

38. Ru ST, Chan MY, Wee ST, Kok FT, Kheng SN, et al. (2012) Stroke prevention in atrial fibrillation: understanding the new oral anticoagulants dabigatran rivaroxaban, and apixaban. Thrombosis 2012: 108983.

39. Bristol-Myers Squibb, Pfizer EEIG (2012) Eliquis ${ }^{\circledR}$ (apixaban) Summary of Product Characteristics.

40. Watson J, Whiteside G, Perry C (2011) Apixaban: first global approval. Drugs 71: 2079-2089

41. Granger CB, Alexander JH, McMurray JJ, Lopes RD, Hylek EM, et al. (2011) Apixaban versus warfarin in patients with atrial fibrillation. N Engl J Med 365 981-992.

42. Bristol-Myers Squibb Canada Inc, Pfizer Canada Inc (2012) Eliquis (apixaban) Product Monograph. 
Citation: Cox JL (2014) Practical Management of Stroke Prevention in Patients with Atrial Fibrillation and Renal Impairment Receiving Newer Oral Anticoagulants: Focus on Rivaroxaban. J Gen Pract 2: 144. doi: 10.4172/2329-9126.1000144

43. Kubitza D, Becka M, Wensing G, Voith B, Zuehlsdorf M (2005) Safety, pharmacodynamics, and pharmacokinetics of BAY 59-7939 - an oral, direct Factor Xa inhibitor - after multiple dosing in healthy male subjects. Eur J Clin Pharmacol 61: 873-880.

44. Gage BF, Waterman AD, Shannon W, Boechler M, Rich MW, et al. (2001) Validation of clinical classification schemes for predicting stroke: results from the National Registry of Atrial Fibrillation. JAMA 285: 2864-2870.

45. Lip GYH, Nieuwlaat R, Pisters R, Lane D, Crijns H (2010) Refining clinical risk stratification for predicting stroke and thromboembolism in atrial fibrillation using a novel risk factor based approach: The Euro Heart Survey on Atria Fibrillation. Chest 137: 263-272.

46. Pisters R, Lane DA, Nieuwlaat R, de Vos CB, Crijns HJ, et al. (2010) A nove user-friendly score (HAS-BLED) to assess 1-year risk of major bleeding in patients with atrial fibrillation: the Euro Heart Survey. Chest 138: 1093-1100.

47. Lip GYH (2011) Chronic renal disease and stroke in atrial fibrillation: balancing the prevention of thromboembolism and bleeding risk. Europace 13: 145-148.

48. Poli D, Antonucci E, Zanazzi M, Grifoni E, Testa S, et al. (2012) Impact of glomerular filtration estimate on bleeding risk in very old patients treated with vitamin K antagonists. Results of EPICA study on the behalf of FCSA (Italian Federation of Anticoagulation Clinics). Thromb Haemost 107: 1100-1106.

49. Fang MC, Go AS, Chang Y, Borowsky LH, Pomernacki NK, et al. (2011) A new risk scheme to predict warfarin-associated hemorrhage: The ATRIA (Anticoagulation and Risk Factors in Atrial Fibrillation) Study. J Am Coll Cardio 58: $395-401$

50. Steffel J, Hindricks G (2012) Apixaban in renal insufficiency: successful navigation between the Scylla and Charybdis. Eur Heart J 33: 2766-2768.

51. Heidbuchel H, Verhamme P, Alings M, Antz M, Hacke W, et al. (2013) European Heart Rhythm Association Practical Guide on the use of new oral anticoagulants in patients with non-valvular atrial fibrillation. Europace 15: 625-651.

52. Turpie AGG, Kreutz R, Llau J, Norrving B, Haas S (2012) Managemen consensus guidance for the use of rivaroxaban - an oral, direct Factor Xa inhibitor. Thromb Haemost 108: 876-886.

53. Kubitza D, Becka M, Mueck W, Halabi A, Maatouk H, et al. (2010) Effects of renal impairment on the pharmacokinetics, pharmacodynamics and safety of rivaroxaban, an oral, direct Factor Xa inhibitor. Br J Clin Pharmacol 70: 703712

54. Bayer Inc (2013) Product Monograph (Canada).

55. Bayer Pharma AG (2013) Xarelto ${ }^{\circledR}$ (rivaroxaban) Summary of Product Characteristics.

56. Janssen Pharmaceuticals Inc (2013) Xarelto $^{\circledR}$ (rivaroxaban) Prescribing Information.

57. Mueck W, Lensing AW, Agnelli G, Decousus H, Prandoni $P$, et al. (2011) Rivaroxaban: population pharmacokinetic analyses in patients treated for acute deep-vein thrombosis and exposure simulations in patients with atrial fibrillation treated for stroke prevention. Clin Pharmacokinet 50: 675-686.

58. Uchino S, Kellum JA, Bellomo R, Doig GS, Morimatsu H, et al. (2005) Acute renal failure in critically ill patients: a multinational, multicenter study. JAMA 294: 813-818.

59. Hilton R (2006) Acute renal failure. BMJ 333: 786-790.

60. Yegenaga I, Hoste E, Van Biesen W, Vanholder R, Benoit D, et al. (2004) Clinical characteristics of patients developing ARF due to sepsis/systemic inflammatory response syndrome: results of a prospective study. Am J Kidney Dis 43: 817-824.

61. Chertow GM, Levy EM, Hammermeister KE, Grover F, Daley J (1998) Independent association between acute renal failure and mortality following cardiac surgery. Am J Med 104: 343-348.

62. Thakar CV, Arrigain S, Worley S, Yared JP, Paganini EP (2005) A clinical score to predict acute renal failure after cardiac surgery. J Am Soc Nephrol 16: 162 168.

63. Weisbord SD, Bernardini J, Mor MK, Hartwig KC, Nicoletta PJ, et al. (2006) The effect of coronary angiography on residual renal function in patients on peritoneal dialysis. Clin Cardiol 29: 494-497.

64. Girman CJ, Kou TD, Brodovicz K, Alexander CM, O’Neill EA, et al. (2012) Risk of acute renal failure in patients with Type 2 diabetes mellitus. Diabet Med 29 : 614-621.
65. Grenfell A (1986) Acute renal failure in diabetics. Intensive Care Med 12: 6-12.

66. Bosch X, Poch E, Grau JM (2009) Rhabdomyolysis and acute kidney injury. N Engl J Med 361: 62-72.

67. Silvester W, Bellomo R, Cole L (2001) Epidemiology, management, and outcome of severe acute renal failure of critical illness in Australia. Crit Care Med 29: 1910-1915

68. Hsu CY, Ordonez JD, Chertow GM, Fan D, McCulloch CE, et al. (2008) The risk of acute renal failure in patients with chronic kidney disease. Kidney Int 74: 101-107.

69. Brochard L, Abroug F, Brenner M, Broccard AF, Danner RL, et al. (2010) An official ATS/ERS/ESICM/SCCM/SRLF statement: prevention and management of acute renal failure in the ICU patient: an international consensus conference in intensive care medicine. Am J Respir Crit Care Med 181: 1128-1155.

70. Needham E (2005) Management of acute renal failure. Am Fam Physician 72 1739-1746.

71. Breton G, Froissart M, Janus N, Launay-Vacher V, Berr C, et al. (2011) Inappropriate drug use and mortality in community-dwelling elderly with impaired kidney function--the Three-City population-based study. Nephrol Dial Transplant 26: 2852-2859.

72. Aronoff GR, Berns JS, Brier ME, Golper TE, Morrison G, et al. (1999) Drug prescribing in renal failure: dosing guidelines for adults, Philadelphia: American College of Physicians.

73. Doshi JA, Shaffer T, Briesacher BA (2005) National estimates of medication use in nursing homes: findings from the 1997 medicare current beneficiary survey and the 1996 medical expenditure survey. J Am Geriatr Soc 53: 438-443.

74. Canadian Institute for Health Information (2010) Drug use among seniors on public drug programs in Canada, 2002 to 2008.

75. Gurwitz JH, Field TS, Judge J, Rochon P, Harrold LR, et al. (2005) The incidence of adverse drug events in two large academic long-term care facilities. Am J Med 118: 251-258.

76. Gurwitz JH, Field TS, Radford MJ, Harrold LR, Becker R, et al. (2007) The safety of warfarin therapy in the nursing home setting. Am J Med 120: 539-544.

77. Beauloye C, CHU Mont-Godinne writing and review committee (2012) Rivaroxaban: a practical guide $\mathrm{V} 1.0$

78. Peacock WF, Gearhart MM, Mills RM (2012) Emergency management of bleeding associated with old and new oral anticoagulants. Clin Cardiol 35: 730737.

79. Samama MM, Martinoli JL, Le Flem L, Guinet C, Plu-Bureau G, et al. (2010) Assessment of laboratory assays to measure rivaroxaban - an oral, direct Factor Xa inhibitor. Thromb Haemost 103: 815-825.

80. Weinz C, Buetehorn U, Daehler HP, Kohlsdorfer C, Pleiss U, et al. (2005) Pharmacokinetics of BAY 59-7939 - an oral, direct Factor Xa inhibitor - in rats and dogs. Xenobiotica 35: 891-910.

81. Lubetsky A, Yonath H, Olchovsky D, Loebstein R, Halkin H, et al. (2003) Comparison of oral vs intravenous phytonadione (vitamin K1) in patients with excessive anticoagulation: a prospective randomized controlled study. Arch Intern Med 163: 2469-2473.

82. Vang ML, Hvas AM, Ravn HB (2011) Urgent reversal of vitamin K antagonis therapy. Acta Anaesthesiol Scand 55: 507-516.

83. Dowlatshahi D, Butcher KS, Asdaghi N, Nahirniak S, Bernbaum ML, et al. (2012) Poor prognosis in warfarin-associated intracranial hemorrhage despite anticoagulation reversal. Stroke 43: 1812-1817.

84. Dentali F, Marchesi C, Pierfranceschi MG, Crowther M, Garcia D, et al. (2011) Safety of prothrombin complex concentrates for rapid anticoagulation reversal of vitamin K antagonists. A meta-analysis. Thromb Haemost 106: 429-438.

85. Lu G, DeGuzman FR, Hollenbach SJ, Karbarz MJ, Abe K, et al. (2013) A specific antidote for reversal of anticoagulation by direct and indirect inhibitors of coagulation Factor Xa. Nat Med 19: 446-451.

86. Janssen Press Release (2013) XARELTO $^{\circledR}$ to be studied with Factor Xa inhibitor antidote.

87. Portola Pharmaceuticals (2012) Phase 2 healthy volunteer study to evaluate the ability of PRT064445 to reverse the effects of several blood thinner drugs on laboratory tests. 
Citation: Cox JL (2014) Practical Management of Stroke Prevention in Patients with Atrial Fibrillation and Renal Impairment Receiving Newer Oral Anticoagulants: Focus on Rivaroxaban. J Gen Pract 2: 144. doi: 10.4172/2329-9126.1000144

Page 9 of 9

88. Douketis JD, Berger PB, Dunn AS, Jaffer AK, Spyropoulos AC, et al. (2008) The perioperative management of antithrombotic therapy: American College of Chest Physicians evidence-based clinical practice guidelines (8th Edition). Chest 133: 299S-339S.

89. Dunn AS, Turpie AGG (2003) Perioperative management of patients receiving oral anticoagulants: a systematic review. Arch Intern Med 163: 901-908.

90. van Ryn J, Stangier J, Haertter S, Liesenfeld KH, Wienen W, et al. (2010) Dabigatran etexilate - a novel, reversible, oral direct thrombin inhibitor: Interpretation of coagulation assays and reversal of anticoagulant activity. Thromb Haemost 103: 1116-1127.

91. Bounameaux H, Reber G (2010) New oral antithrombotics: a need for laboratory monitoring. Against. J Thromb Haemost 8: 627-630.
92. Mismetti P, Laporte S (2010) New oral antithrombotics: a need for laboratory monitoring. For. J Thromb Haemost 8: 621-626.

93. Coleman Cl, Roberts MS, Sobieraj DM, Lee S, Alam T, et al. (2012) Effect of dosing frequency on chronic cardiovascular disease medication adherence. Curr Med Res Opin 28: 669-680.

94. Laliberte F, Nelson WW, Lefebvre P, Schein JR, Rondeau-Leclaire J, et al (2012) Impact of daily dosing frequency on adherence to chronic medications among nonvalvular atrial fibrillation patients. Adv Ther 29: 675-690.

95. Boehringer Ingelheim Canada Ltd (2012) Pradax ${ }^{\mathrm{TM}}$ (dabigatran etexilate mesilate) Product Monograph.

96. Bristol-Myers Squibb Company, Pfizer Inc (2012) Eliquis ${ }^{\circledR}$ (apixaban) Prescribing information. 